\title{
Backstepping control of two-mass system using induction motor drive fed by voltage source inverter with ideal control performance of stator current
}

\author{
Vo Thanh Ha, Le Trong Tan, Nguyen Duc Nam, Nguyen Phung Quang \\ Institute for Control Engineering and Automation- ICEA, Hanoi University of Science and Technology, Vietnam
}

\begin{tabular}{l} 
Article Info \\
\hline Article history: \\
Received Oct 10, 2018 \\
Revised Nov 19, 2018 \\
Accepted Mar 3, 2019 \\
\hline Keywords: \\
Backstepping controller \\
Drive induction motor \\
Performance of stator current \\
Reduced-order mathematical \\
mode \\
Two-mass system
\end{tabular}

\section{Article history:}

Received Oct 10, 2018

Revised Nov 19, 2018

Accepted Mar 3, 2019

\section{Keywords: \\ Performance of stator current mode}

\begin{abstract}
This paper describes the design and the simulation of a non-linear controller for two-mass system using induction motor basing on the backstepping method. The aim is to control the speed actual value of load motor matching with the speed reference load motor, moreover, electrical drive's respone ensuring the "fast, accurate and small overshoot" and reducing the resonance oscillations for two-mass system using induction motor fed by voltage source inveter with ideally control performance of stator current. Backstepping controller uses the non-linear equations of an induction motor and the linear dynamical equations of two-mass system, the Lyapunov analysis and the errors between the real and the desired values. The controller has been implemented in both simulation and hardware-in-the-loop (HIL) real-time experiments using Typhoon HIL 402 system, when the drive system operates at a stable speed (rotor flux is constant) and greater than rated speed (field weakening area). The simulation and HIL results presented the correctness and effectiveness of the controller is proposed; furthermore, compared to PI method to see the response of the system clearly.
\end{abstract}

Copyright (C) 2019 Institute of Advanced Engineering and Science. All rights reserved.

\section{Corresponding Author:}

Nguyen Phung Quang, Institute for Control Engineering and Automation- ICEA, Hanoi University of Science and Technology,

No.1, Dai Co Viet Road, Hai Ba Trung, Hanoi, Vietnam.

Email: quang.nguyenphung@hust.edu.vn

\section{INTRODUCTION}

The two-mass system with flexible shaft can be found in many industrial applications such as machine tools, rolling-mills, robot arms, conveyer belts, etc. Due to the finite stiffness and damping coefficients of the shaft, the speed oscillation of the drive system is inevitable and may cause detrimental influences on not only the quality of the products but also the mechanical and electrical components of the drive system. Hence, speed control design for these drive systems plays a key role in improving the system characteristic and products quality. Suppressing the shaft torsional vibration, rejecting the load disturbance torque and tracking the reference speed are main goals of the controller [1-4]. However, these tasks are not easy to be achieved due to the fact that not all system state variables are available. Furthermore, unknown nonlinearities such as friction and backlash may also cause undesirable inaccuracy for the control system.

Various control schemes have been developed in the literature to suppress the torsional vibration of the aforementioned two-mass system. Obviously, the classical cascade structure using proportional-integral (PI) speed controller is the most popular control scheme. However, this method cannot effectively suppress the vibration since the PI controller does not have enough degree-of-freedom to handle such high order dynamic system like this [5]. Thus, advanced control techniques such as sliding mode control, flatness-based control, adaptive control, and fuzzy adaptive control are also employed to get a better performance [6-11]. 
In this research, the field-oriented control (FOC) which has been widely used in industrial inverters is used to control the induction motor of the drive system [12]. Based on an observation that if the response of the stator current controller is fast enough, the order of the two-mass dynamic system can be reduced from 7th to 3rd in nominal speed range and from 7th to 4th in field weakening range. Consequently, the control design for the reduced order system can be simplified. Since the dead-beat controller, which forces the stator current to its desired value in finite step, has already successfully been developed for the stator current loop in our previous study [13], the remaining objective of this research is to achieve a high dynamic speed control with torsional oscillation reduction for the drive system.

In this paper, a backstepping control algorithm is proposed to control the load speed of two-mass systems. For achieving this goal, a two-block control strategy is proposed. It is backstepping control algorithm for load speed and motor speed. On the other hand, rotor flux control is designed acording to backstepping control algorithm. Generating the desired motor torque by dead-beat current control, not only guarantees accurate load speed but also proves the stability of the system $[14,15]$.

\section{MODELING OF DRIVE SYSTEM}

\subsection{Mathematical model of three phase induction motor}

In field synchronous coordinate, the three-phase induction motor canbe described by the following dynamic equations [12].

$$
\left\{\begin{array}{l}
\frac{d i_{s d}}{d t}=-\left(\frac{1}{\sigma T_{s}}+\frac{1-\sigma}{\sigma T_{r}}\right) i_{s d}+\omega_{s} i_{s q}+\frac{1-\sigma}{\sigma T_{r}}+\frac{1}{\sigma L_{s}} u_{s d} \\
\frac{d i_{s q}}{d t}=-\omega_{s} i_{s d}-\left(\frac{1}{\sigma T_{s}}+\frac{1-\sigma}{\sigma T_{r}}\right) i_{s q}-\frac{1-\sigma}{\sigma} \omega i_{m}+\frac{1}{\sigma L_{s}} u_{s q} \\
\frac{d i_{m}}{d t}=-\frac{1}{T_{r}} i_{m}+\frac{1}{T_{r}} i_{s d} \\
\frac{d \omega}{d t}=k i_{m} i_{s q}-\frac{z_{p}}{J} m_{L}
\end{array}\right.
$$

In which, $i_{s d} ; i_{s q}$ are $d q$ components of the stator current; $\omega, \omega_{s}$ are mechanical rotor velocity and synchronous speed, respectively; $\psi_{r d}^{\prime}, \psi_{r q}^{\prime}$ are dq components of the rotor flux; $\sigma$ is total leakage factor; $T_{r}$ is rotor time constat: ${ }^{u_{s d}}, u_{s q}$ are $d q$ components of the stator voltage; $L_{s}$ is stator inductance.

It can be seen that the original state (1) is bilinear and is of $4^{\text {th }}$ order. Assume that the current controller is perfect with ideal response, the induction motor model can be reduced as:

$$
\left\{\begin{array}{l}
\frac{d i_{m}}{d t}=-\frac{1}{T_{r}} i_{m}+\frac{1}{T_{r}} i_{s d} \\
\frac{d \omega}{d t}=k i_{m} i_{s q}-\frac{z_{p}}{J} m_{L}
\end{array}\right.
$$

Where:

$$
i_{m}=\frac{\psi_{r d}}{L_{m}} ; k=\frac{3}{2} \frac{z_{p}^{2} L_{m}^{2}}{L_{r} J}
$$

In which, $L_{m}, L_{r}$ is mutual, rotor inductance; $i_{m}$ is vector of magnetizing current; ${ }^{m}{ }_{L}$ is torque load; $Z_{p}$ is number of pole pairs; $J$ is torque of inertia;

The state (2) is of $2^{\text {nd }}$ order, stator current $i_{s d}$ is used to control the motor flux and $i_{s q}$ is dedicated to speed control.

\subsection{Model of the two-mass system}

Typical configuration of a two-mass system show as Figure 1:

Backstepping control of two-mass system using induction motor drive fed... (Nguyen Phung Quang) 


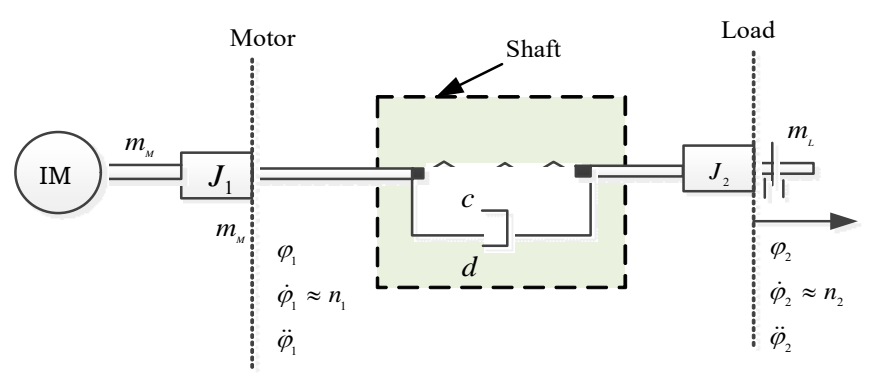

Figure 1. Typical configuration of a two-mass system

The typical configuration of a two-mass system is illustrated in Figure 1. The system can be described by the following linear dynamical equations [2].

$$
\left\{\begin{array}{l}
\ddot{\varphi}_{1}=-\frac{d}{J_{1}} \dot{\varphi}_{1}-\frac{c}{J_{1}} \Delta \varphi+\frac{d}{J_{1}} \dot{\varphi}_{2}+\frac{1}{J_{1}} m_{M} \\
\Delta \dot{\varphi}=\dot{\varphi}_{1}-\dot{\varphi}_{2} \\
\ddot{\varphi}_{2}=\frac{d}{J_{2}} \dot{\varphi}_{1}+\frac{c}{J_{2}} \Delta \varphi-\frac{d}{J_{2}} \dot{\varphi}_{2}-\frac{1}{J_{2}} m_{L}
\end{array}\right.
$$

Where:

$\dot{\varphi}_{1}, \dot{\varphi}_{2}$ Are motor speed, load speed; $\ddot{\varphi}_{1}, \ddot{\varphi}_{2}$ are motor and load angle acceleration; $\varphi_{\text {is angle; } d \text { is }}$ shaft damping coefficient; $C_{\text {is shaft stiffness. }}$

When the drive system operates at field weakening range, the mathematical model of the system is [2].

$$
\left\{\begin{array}{l}
\frac{d i_{m}}{d t}=\frac{1}{T_{r}} i_{s d}-\frac{1}{T_{r}} i_{m} \\
\ddot{\varphi}_{1}=-\frac{d}{J_{1}} \dot{\varphi}_{1}-\frac{c}{J_{1}} \Delta \varphi+\frac{d}{J_{1}} \dot{\varphi}_{2}+\frac{1}{J_{1}} m_{M} \\
\Delta \dot{\varphi}=\dot{\varphi}_{1}-\dot{\varphi}_{2} \\
\ddot{\varphi}_{2}=\frac{d}{J_{2}} \dot{\varphi}_{1}+\frac{c}{J_{2}} \Delta \varphi-\frac{d}{J_{2}} \dot{\varphi}_{2}-\frac{1}{J_{2}} m_{L}
\end{array}\right.
$$

For control design purpose, term (4) is rewritten in the following state-space form:

$$
\left[\begin{array}{c}
\dot{i}_{m} \\
\ddot{\varphi}_{1} \\
\Delta \dot{\varphi} \\
\ddot{\varphi}_{2}
\end{array}\right]=\left[\begin{array}{cccc}
\frac{-1}{T_{r}} & 0 & 0 & 0 \\
0 & \frac{-d}{J_{1}} & \frac{-c}{J_{1}} & \frac{d}{J_{1}} \\
0 & 1 & 0 & -1 \\
0 & \frac{d}{J_{2}} & \frac{c}{J_{2}} & \frac{-d}{J_{2}}
\end{array}\right]\left[\begin{array}{c}
i_{m} \\
\dot{\varphi}_{1} \\
\Delta \varphi \\
\dot{\varphi}_{2}
\end{array}\right]+\left[\begin{array}{cc}
\frac{1}{T_{r}} & 0 \\
0 & \frac{k_{w} i_{m}}{J_{1}} \\
0 & 0 \\
0 & 0
\end{array}\right]\left[\begin{array}{c}
i_{s d} \\
i_{s q}
\end{array}\right]+\left[\begin{array}{c}
0 \\
0 \\
0 \\
\frac{-1}{J_{2}}
\end{array}\right] m_{L}
$$

With:

$$
y^{I}=i_{m}, \dot{\varphi}_{2} ;\left[\begin{array}{l}
i_{m} \\
\dot{\varphi}_{2}
\end{array}\right]=\left[\begin{array}{cccc}
1 & 0 & 0 & 0 \\
0 & 0 & 0 & 1
\end{array}\right]\left[\begin{array}{c}
i_{m} \\
\dot{\varphi}_{1} \\
\Delta \varphi \\
\dot{\varphi}_{2}
\end{array}\right]
$$




\section{BACKSTEPPING CONTROL DESIGN FOR THE FLUX AND SPEED CONTROL}

Based on [13] and the concept of the backstepping design for induction motor [10], the proposed control scheme for the two-mass system using induction motor fed by VSI with perfect stator current controller is shown in Figure 2.

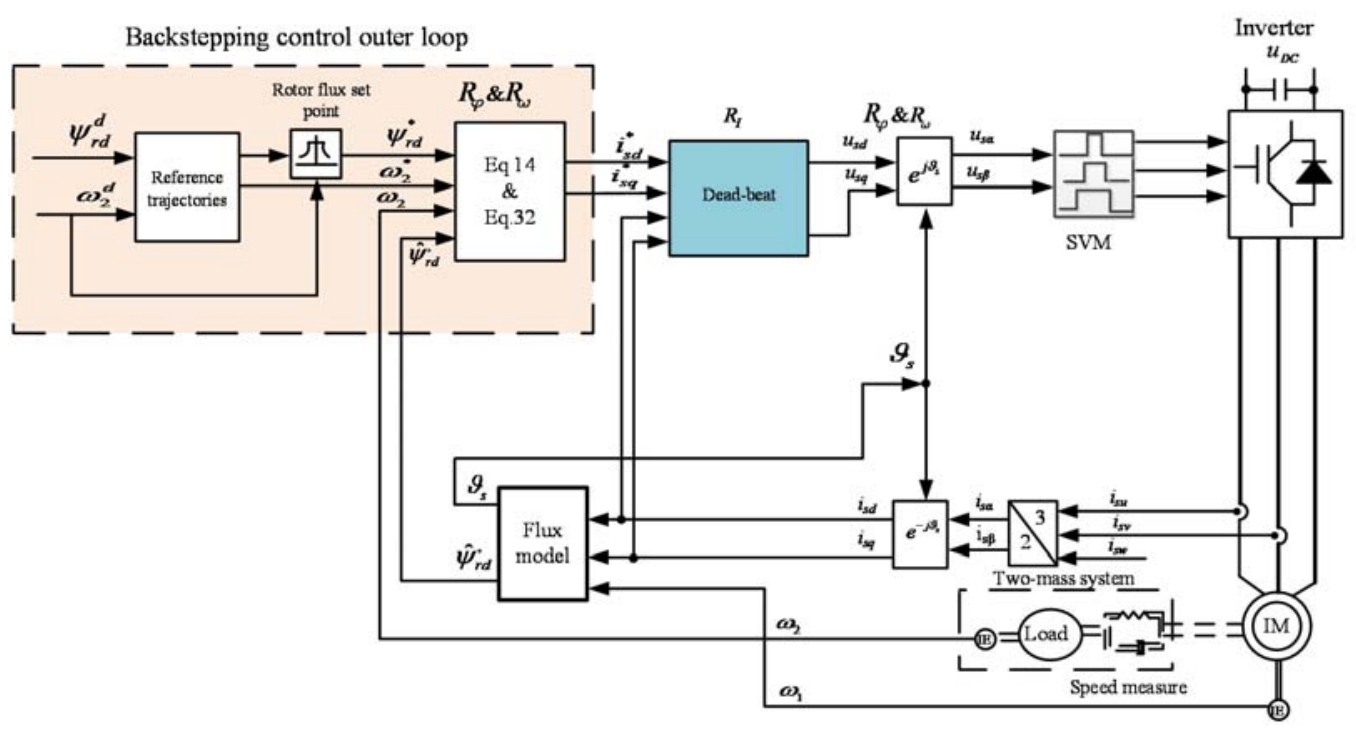

Figure 2. Block diagram control of two-mass system

In this section, a backstepping control stagegy is proposed to control the rotor flux and speed load of two-mass system with flexible couplings. This paper presented the induction motors operate at rated require speed is greater than the rated speed; therefore, the flux must be reduced to ensure that the power supply is not overloaded.

\subsection{Flux controller design}

Since rotor flux magnitude are our control variables, the tracking errors are defined by:

$$
z_{1}=i_{m}-i_{m}^{*}\left(i_{m}^{*} \text { is the desired value of flux }\right)
$$

taking the derivative of both sides of (7) Gives:

$$
\dot{z}_{1}=\frac{d i_{m}}{d t}-\frac{d i_{m}^{*}}{d t}=-\frac{1}{T_{r}} i_{m}+\frac{1}{T_{r}} i_{s d}-\frac{d i_{m}^{*}}{d t}
$$

we can see that (8) is the non-linear equation $\frac{d \mathbf{x}}{d t}=f(\mathbf{x}, \mathbf{u}, t)$

where:

$z_{1}$ is the state variable; $i_{s d}$ is the input signal (or control signal).

to stabilize the flux signal given by (8), the candidate Lyapunov fuction can be defined as following:

$$
V\left(z_{1}\right)=\frac{1}{2} z_{1}^{2} \geq 0
$$

which the derivative of (9) is:

$$
\dot{V}\left(z_{1}\right)=z_{1} \dot{z}_{1}=z_{1}\left(-\frac{1}{T_{r}} i_{m}+\frac{1}{T_{r}} i_{s d}-\frac{d i_{m}^{*}}{d t}\right)
$$


The Lyapunov stability condition can be verified if the stabilization function $\dot{V}\left(z_{1}\right)$ is chosen as follows:

$$
\dot{V}\left(z_{1}\right)=-c_{1} z_{1}^{2} \leq 0 \forall z_{1}
$$

where ${ }^{C_{1}}$ is the positive constant design that is determine the closed-loop dynamics Substitute (11) into (10) Result in:

$$
i_{s d}=-c_{1} T_{r} z_{1}+i_{m}+T_{r} \frac{d i_{m}^{*}}{d t}
$$

with: $\left\{\begin{array}{l}\dot{i}_{s d}^{*} \approx i_{s d} \\ i_{s q}^{*} \approx i_{s q}\end{array}\right.$

The (12) as shown:

$$
i_{s d}^{*}=-c_{1} T_{r} z_{1}+i_{m}+T_{r} \frac{d i_{m}^{*}}{d t}
$$

so, the $i_{s d}^{*}$ is the actual control signal, the control rule for the flux controller.

\subsection{Speed controller design}

For designing this nonlinear control law, it is assumed that all feedback signals from the motor, the shaft and the load sides are available in this section. As Figure 3 shows, the proposed backstepping control algorithm is designed in two steps. In each step a subsystem will be studied. Each step includes the dynamics of the previous subsystems for backstepping technique. Selecting a proper Lyapunov function for each step, guarantees the asymptotic stability of the related subsystem. Completing all two steps, results in not only the asymptotic stability of the whole system, but also the desired input (motor torque) law for accurate load speed control.

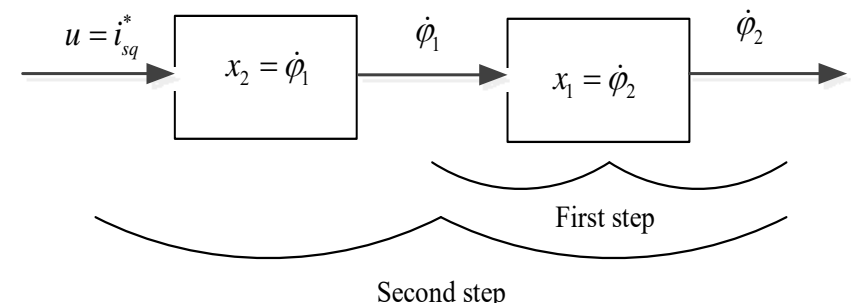

Figure 3. Block diagram of two-step backstepping control algorithm of a two-mass system

The speed control equation is given:

$$
\left\{\begin{array}{l}
\ddot{\varphi}_{1}=\frac{1}{J_{1}} k_{\omega} i_{m} i_{s q}-\frac{c}{J_{1}} \Delta \varphi-\frac{d}{J_{1}} \dot{\varphi}_{1}+\frac{d}{J_{1}} \dot{\varphi}_{2} \\
\ddot{\varphi}_{2}=\frac{d}{J_{2}} \dot{\varphi}_{1}+\frac{c}{J_{2}} \Delta \varphi-\frac{d}{J_{2}} \dot{\varphi}_{2}-\frac{1}{J_{2}} m_{L}
\end{array}\right.
$$


The (15) has triangular form as follows:

$$
\left\{\begin{array}{l}
\frac{d\left(\dot{\varphi}_{2}\right)}{d t}=f\left(\dot{\varphi}_{2}, \dot{\varphi}_{1}\right) \\
\frac{d\left(\dot{\varphi}_{1}\right)}{d t}=f\left(\left[\dot{\varphi}_{2}, \dot{\varphi}_{1}\right], i_{s q}\right)
\end{array}\right.
$$

these two step for designing the backstepping control law are mentioned in the following:

Step 1: apply the backstepping for load speed $\dot{\varphi}_{2}$ :

Since load speed magnitude are our control variables, the tracking errors are defined by:

$$
z_{2}=\dot{\varphi}_{2 d}-\dot{\varphi}_{2}\left(\dot{\varphi}_{2}\right. \text { Is the reference load speed) }
$$

taking the derivative of both sides of (17) Gives:

$$
\dot{z}_{2}=\ddot{\varphi}_{2 d}-\ddot{\varphi}_{2}
$$

to stabilize the flux signal given by (18), the candidate Lyapunov fuction can be defined as following:

$$
V\left(z_{2}\right)=\frac{1}{2} z_{2}^{2} \geq 0
$$

which the derivative of (19) Is:

$$
\dot{V}\left(z_{2}\right)=z_{2} \dot{z_{2}}
$$

then:

$$
-z_{2}=-\dot{\varphi}_{1}-\frac{c}{d} \Delta \varphi+\dot{\varphi}_{2}+\frac{1}{d} m_{L}
$$

the (21) Is result in:

$$
\dot{\varphi}_{1}=\dot{\varphi}_{2 d}+\frac{1}{d} m_{L}-\frac{c}{d} \Delta \varphi
$$
follows:

The Lyapunov stability condition can be verified if the stabilization function $\dot{V}\left(z_{2}\right)$ is chosen as

$$
\dot{V}\left(z_{2}\right)=-\frac{d}{J_{2}} z_{2}^{2} \leq 0 \forall z_{2}
$$

where $d$ is the positive constant design that is determine the closed-loop dynamics.

From (18) and (15) We obtain:

$$
-\frac{d}{J_{2}} z_{2}^{2}=z_{2}\left(\ddot{\varphi}_{2 d}-\frac{d}{J_{2}} \dot{\varphi}_{1}-\frac{c}{J_{2}} \Delta \varphi+\frac{d}{J_{2}} \dot{\varphi}_{2}+\frac{1}{J_{2}} m_{L}\right)
$$

then

$$
\left.-z_{2}=-\dot{\varphi}_{1}-\frac{c}{d} \Delta \varphi+\dot{\varphi}_{2}+\frac{1}{d} m_{L}\right)
$$

so load speed shown as: 


$$
\dot{\varphi}_{1}=\dot{\varphi}_{2 d}+\frac{1}{d} m_{L}-\frac{c}{d} \Delta \varphi
$$

Step 2: apply the backstepping for motor speed ( $\left.\dot{\varphi}_{1}\right)$ :

Since load speed magnitude are our control variables, the tracking errors are defined by:

$z_{1}=\dot{\varphi}_{1 d}-\dot{\varphi}_{1}\left(\dot{\varphi}_{1 d}\right.$ Is the reference motor speed)

taking the derivative of both sides of (27) Gives:

$$
\dot{z}_{1}=\ddot{\varphi}_{1 d}-\ddot{\varphi}_{1}
$$
following:

To stabilize the flux signal given by (28), the candidate Lyapunov fuction can be defined as

$$
V_{1}=\frac{1}{2} z_{2}^{2}+\frac{1}{2} z_{1}^{2}
$$

which the derivative of (29) is:

$$
\dot{V}_{1}=z_{2} \dot{z}_{2}+z_{1} \dot{z}_{1}
$$

then substitute (15) and (28) into (30), we get

$$
\left\{\begin{array}{l}
\ddot{\varphi}_{1 d}-\frac{1}{J_{1}} k_{\omega} i_{m} i_{s q}+\frac{c}{J_{1}} \Delta \varphi+\frac{d}{J_{1}} \dot{\varphi}_{1 d}-\frac{d}{J_{1}} \dot{\varphi}_{2}+\frac{d}{J_{2}} z_{2}=0 \\
\ddot{\varphi}_{2 d}+\frac{d}{J_{2}} \dot{\varphi}_{1 d}-\frac{c}{J_{2}} \Delta \varphi+\frac{d}{J_{2}} \dot{\varphi}_{2 d}+\frac{1}{J_{2}} m_{L}=0
\end{array}\right.
$$

the (31) is result in:

$$
i_{s q}=\frac{1}{k_{\omega} i_{m}}\left(c \Delta \varphi+d \dot{\varphi}_{1 d}-d \dot{\varphi}_{2}+\frac{d J_{1}}{J_{2}} z_{2}\right)
$$

so, the $i_{s q}^{*}$ is the actual control signal, the control rule for the speed controller.

\subsection{Design the reference trajectories}

When designing the controller, we usually set the desired value to a constant (step-by-step trajectory). At the first interval of time, the large deviation will cause a large input requirement. However, the response of the actuator is finite, it is unlikely that the controller will meet the requirements. Thus the backstepping control method will "soften" the desired signal by changing the desired signal slowly so that the response of the system is soft and better. For this reason, the second order is chosen for designing the reference trajectories. Because the control rules are represented in (14) And (32) Use the first order derivative, the form of trajectories $i_{m}^{*}$ and $\omega^{*}$ will have to be first order differentiable.

Flux reference trajectory designing $i_{m}^{*}$

$$
\frac{i_{m}^{*}(s)}{i_{m}^{d}(s)}=\frac{1}{\left(1+T_{1} s\right)^{2}}=\frac{1}{1+2 T_{1} s+T_{1}^{2} s^{2}}
$$

where: $\quad T_{1}$ is time constant; $i_{m}^{*}$ is output of flux reference trajectory; ${ }_{m}^{d}$ is input of flux reference trajectory. 
Therefore, on the time domain:

$$
T_{1}^{2} \frac{d^{2} i_{m}^{*}}{d t^{2}}+2 T_{1} \frac{d i_{m}^{*}}{d t}+i_{m}^{*}=i_{m}^{d}
$$

trajectories of flux reference:

$$
\frac{d^{2} i_{m}^{*}}{d t^{2}}=\frac{1}{T_{1}^{2}}\left(i_{m}^{d}-i_{m}^{*}-2 T_{1} \frac{d i_{m}^{*}}{d t}\right)
$$

Speed reference trajectory designing $\omega^{*}$

$$
\frac{\omega^{*}(s)}{\omega^{d}(s)}=\frac{1}{\left(1+T_{2} s\right)^{2}}=\frac{1}{1+2 T_{2} s+T_{2}^{2} s^{2}}
$$

where: $T_{2}$ is time constant; $\omega^{*}$ is output of speed reference trajectory; $\omega^{d}$ is input of speed reference trajectory. Therefore, on the time domain:

$$
T_{2}^{2} \frac{d^{2} \omega^{*}}{d t^{2}}+2 T_{2} \frac{d \omega^{*}}{d t}+\omega^{*}=\omega^{d}
$$

trajectories of flux reference:

$$
\frac{d^{2} \omega^{*}}{d t^{2}}=\frac{1}{T_{2}^{2}}\left(\omega^{d}-\omega^{*}-2 T_{2} \frac{d \omega^{*}}{d t}\right)
$$

\section{RESULT AND ANALYSIS}

In this section, the proposed control strategy is verified by simulation using Hardware-in-the-Loop (HIL). The proposed control is also verified in Hardware-in-the-Loop (HIL) environment using a Typhoon device in Figure 4. This device consists of an HIL402 card that simulates grid source, load, and three fullbridge with a common DC-link capacitor using IGBTs. The system hardware is simulated in real time on the HIL platform with a time step of $1 \mu$ s that means very nearly physical model, while the pulse width modulation (PWM) carrier frequency is $5 \mathrm{kHz}$. Voltage and current controllers as well as PLL are implemented in DSP TMS320F2808 card.

The simulation parameters for rated power: $0.5 \mathrm{~kW}$; rated phase voltage: $220 \mathrm{VRMS}$; rated frequency: $50 \mathrm{~Hz} ; \mathrm{d}=0.313 \mathrm{Nm} / \mathrm{rad} / \mathrm{s} ; \mathrm{c}=300000 \mathrm{Nm} / \mathrm{rad}$.

Simulation procedure is as follows:

At $\mathrm{t}=0 \mathrm{~s}$, the magnetic current is created. Then at time instance $\mathrm{t}=0.4 \mathrm{~s}$, the motor starts to speed up to $2500 \mathrm{rpm}$. At $\mathrm{t}=1 \mathrm{~s}$, the full load is inserted. At $\mathrm{t}=1,4 \mathrm{~s}$, the motor is continued to speed up to $3500 \mathrm{rpm}$ with full load. Finally, the motor starts to change the rotating direction with a reference speed, i.e, 2500rpm, at time instance $\mathrm{t}=2.0 \mathrm{~s}$.

The simulation results of the proposed method are presented and compared to those getting from the conventional PI controller to evaluate the advantage of the backstepping method.

The responses of magnetizing current are shown in Figure 5. Both conventional PI and backstepping methods show stable operation not only in nominal but also field weakening range. However, it can be observed that the backstepping gives better transient response, i.e., without overshoot as seen in Figure 5 and shorter settling time ( $0.2 \mathrm{~s}$ in comparison with $0.35 \mathrm{~s}$ for PI control).

The response of the torque, speed as well as torque ripple of the motor are shown in Figure 6. As can be observed, the torque and speed quickly match their commands for both methods. Nevertheless, the backstepping always shows better performance, i.e, lower torque ripple and shorter accelerating time, as can be seen in Figure 7. 


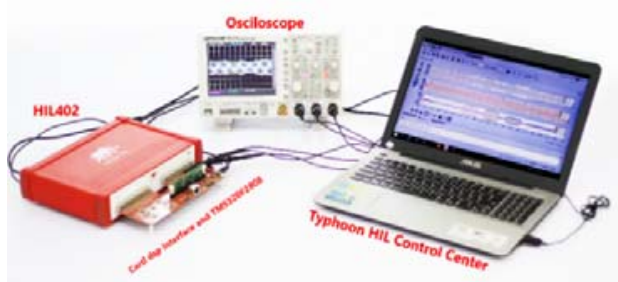

Figure 4. Picture of hardware HIL platform.
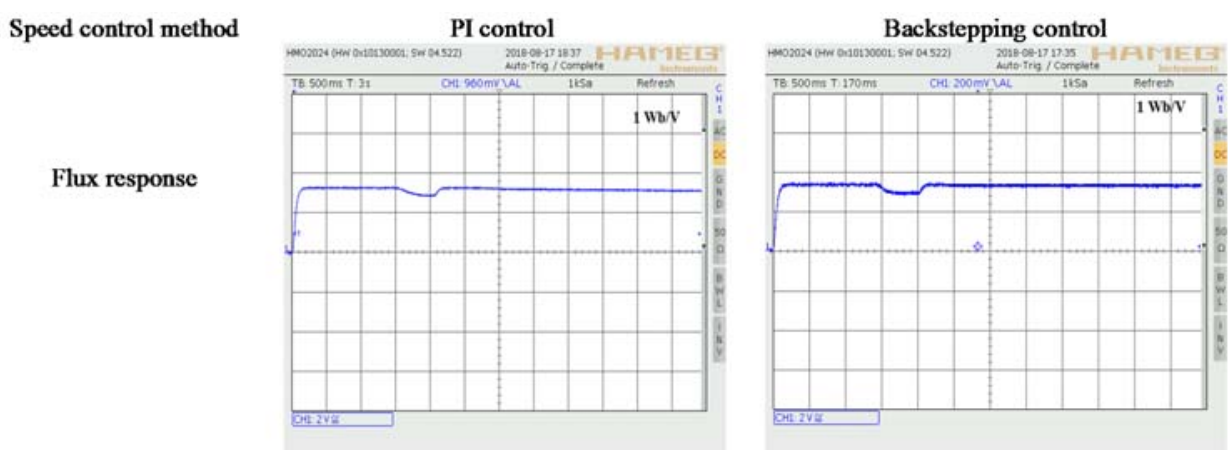

Figure 5. Magnetizing current response
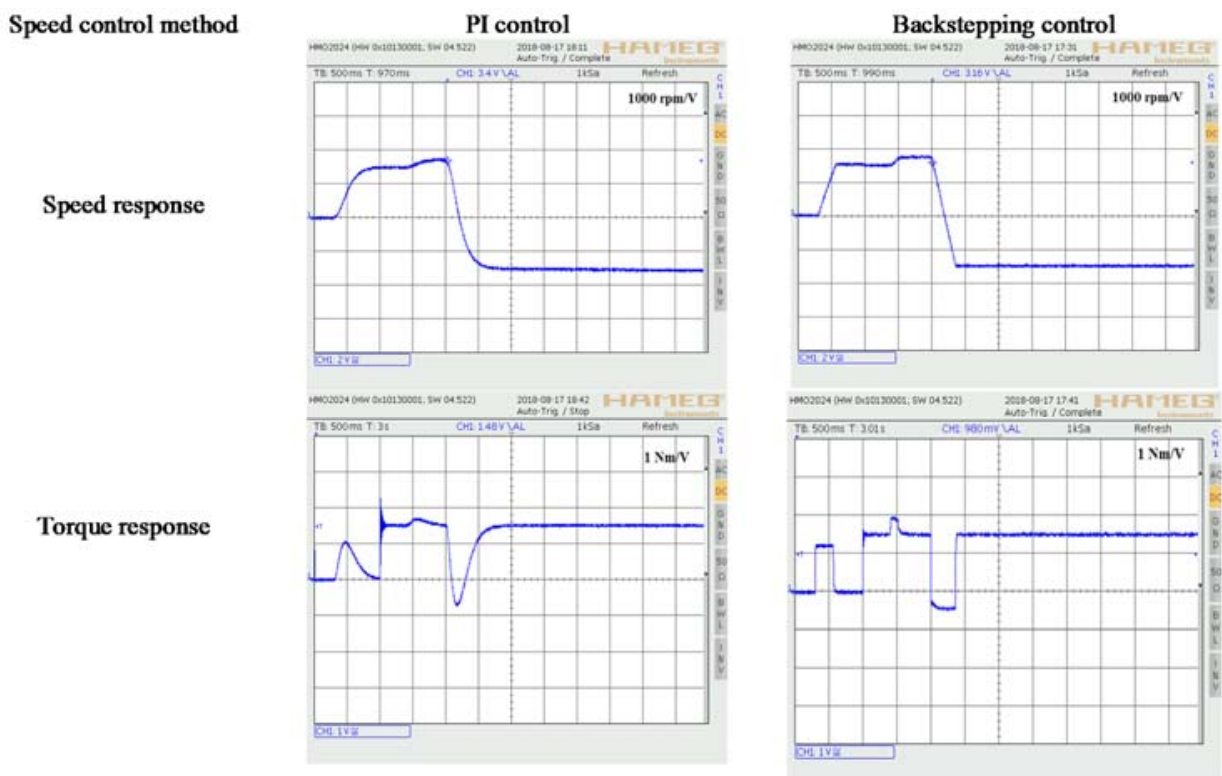

Figure 6. Speed and torque responses 


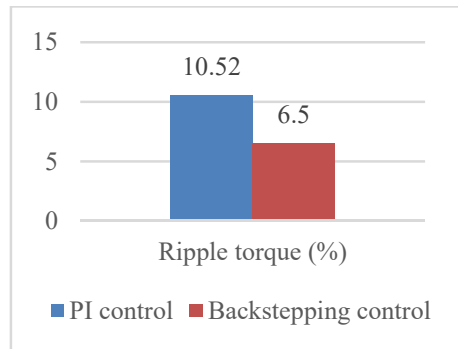

(a)

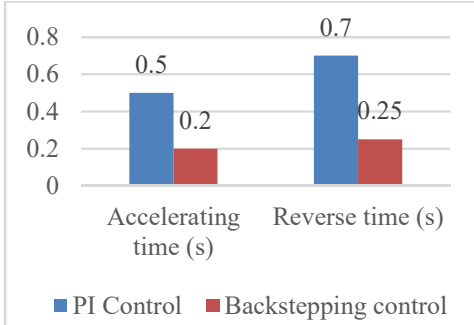

(b)

Figure 7. Chart of torque and speed responses, (a) torque responses, (b) speed responses

\section{CONCLUSION}

In this paper, the two-mass system with flexible couplings comprises of an induction motor and a load is considered. At the motor side, the current response is assumed to be ideal leading to a simplified model. Backstepping control is employed to solve flux and speed control problem of the system. The system can operate at field weakening region. The simulation results show that high dynamic and suppression of the mechanical oscillation of the drive system can be achieved.

\section{ACKNOWLEDGEMENTS}

The authors would like to thanks Institute for Control Engineering and Automation of Ha Noi University of Science and Technology for their assistance.

\section{REFERENCES}

[1] J. Arellano-Padilla, G. M. Asher, and M. Sumner, "Control of a dynamometer for dynamic emulation of mechanical loads with stiff and flexible shafts," IEEE Trans. Ind. Electron, vol. 53(4), pp. 1250-1260, 2006.

[2] Ghazanfer Shahgholian, Jawad Faiz, Pegah Shafaghi, "Modeling and Simulation of a Two-Mass Resonant System with Speed Controller," International Journal of Information and Electronics Engineering, vol. 3(5), September 2013.

[3] Mattias Nordin, "Per-Olof Gutman Controlling mechanical systems with backlash—a survey," Automatica, vol. 38, pp. 1633-1649, 2002.

[4] Y. S. Kim, S. B. Kim, J. S. Kim, C. H. Yoo, H. J. Kim," Two degree of freedom speed control of induction motor having two mass resonant system," IEEE/IECON, vol. 2, pp. 1210-1215, Aug. 1996.

[5] K. Szabat and T. Orlowska-Kowalska, "Vibration suppression in two-mass drive system using PI speed controller and additional feedbacks - Comparative study," IEEE Trans.Ind. Electron., vol. 54(2), pp. 1193-1206, 2007.

[6] Karrol Wrobel, "Fuzzy adaptive control of nonlinear two-mass system," International Journal of Power Electronics and Drive Systems (IJPEDS), vol.1(2), Retrieved from DOI:10.5277/PED160208, September 2016.

[7] K. Erenturk, "Nonlinear two-mass system control with slidingmode and optimised proportional-integral derivative controller combined with a grey estimator," Control Theory \& Applications, IET, vol. 2(7), pp. 635-642, July 2008.

[8] S. Thomsen, F. W. Fuchs, "Design and analysis of a flatness-based control approach for speed control of drive systems with elastic couplings and uncertain loads," Proceedings of the 2011 14th European Conference on Power Electronics and Applications. 2001.

[9] Emre Sariyildiz, Haoyong Yu, Takahiro Nozaki, Toshiyuki Murakami, "Robust Vibration Control of Two-Mass Resonant Systems in State Space," IEEE Advanced Motion Control April 22-24, Auckland New Zealand, 2016.

[10] Jacek Kabziński, Przemysław Mosiolek, "Adaptive Control of Two-Mass Drive System with Nonlinear Stiffness," Przeglad Elektrotechniczny, ISSN 0033-2097, R. 94 NR 3/2018, doi:10.15199/48.2018.03.09, September 2016.

[11] R. Gunabalan, V. Subbiah, "Speed Sensorless Vector Control of Induction Motor Drive with PI and Fuzzy Controller," International Journal of Power Electronics and Drive System (IJPEDS), vol. 5(3), pp. 315-325, ISSN: 2088-8694, February 2015.

[12] N. P. Quang and J.-A. Dittrich, "Vector control of three-phase AC machines - System development in the practice, 2nd edition, "Springer, 2015.

[13] Nguyen Phung Quang, Vo Thanh Ha, Tran Vu Trung, "A new control design with dead-beat behavior for stator current vector in three phase AC drive," SSRG International Journal of Electrical and Electronics Engineering (SSRG-IJEEE), vol. 5(4), ISSN:2349-9176, Apr 2018.

[14] Mirhamed Mola, Alireza Khayatian, Maryam Dehghani, "Backstepping Position Control of Two-Mass Systems with Unknown," IEEE 978-1-4673-5769-2/13/\$31.00 @2013.

[15] Marouane El Azzaoui, Hassane Mahmoudi, d Karima Boudaraia, "Backstepping Control of Wind and Photovoltaic Hybrid Renewable Energy System," International Journal of Power Electronics and Drive Systems (IJPEDS), vol. 7(3), pp. 677-686, September 2016.

Backstepping control of two-mass system using induction motor drive fed... (Nguyen Phung Quang) 


\section{BIOGRAPHIES OF AUTHORS}

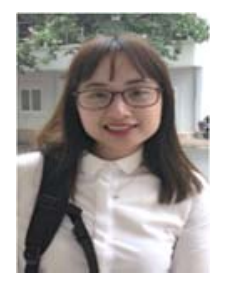

Vo Thanh Ha was born in 1979. She received the Master's degree from Hanoi University of Science and Technology, Vietnam in 2002 and she is currently pursuing $\mathrm{Ph}$. D degree from Hanoi University of Science and Technology, Viet Nam, both in Control and Automation Engineering. She has worked in University of Transport and Communication, as a lecturer for 15 years. Her current areas of research are electrical drive and power electronics.

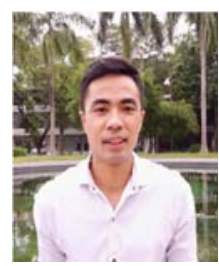

Le Trong Tan was born in 1996. He is a fifth year student with automatic control major at Hanoi University of Science and Technology. Currently, his main research interests are electrical drives and control.

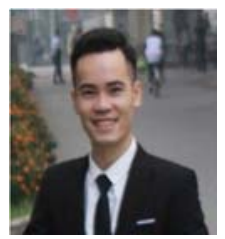

Nguyen Duc Nam was born in 1994. He received the automation engineering degree from Hanoi University of Science and Technology, Vietnam in 2018. He is currently pursuing a Master's degree at Hanoi University of Science and Technology, Vietnam both in Control and Automation Engineering. His research interests are electrical drive and power electronics.

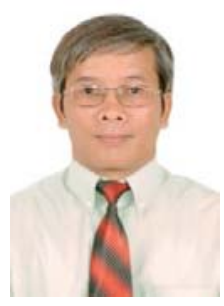

Nguyen Phung Quang

Prof. Dr.-Ing. Habil. Quang Nguyen Phung was born in 1953. He received the Dipl.-Ing. (Uni) degree, the Dr.-Ing. Degree and the Dr.-Ing. Habil all from TU Dresden, Germany in 9/1975, 11/1991 and 4/1994, respectively. He has worked in the German industrial organizations for many years, contributing to the creation of the REFU 402 Vectovar Inverter, RD 500 (REFU Electronik Corporation), Simovert 6SE42, Master Drive MC (Siemens Corporation).

From 1996 to 1998, he was a lecturer at TU Dresden, where he was acknowledged as Privatdozent in 10/1997. The early 1999, he returned to Viet Nam and has been a lecturer at Hanoi University of Science and Technology up to now. TU Dresden confered Honorarprofessor degree on him in 2/2004. He received the Assoc. Prof. degree and Prof. degree in automation engineering from Hanoi University of Science and Technology in 11/2004 and 11/2009, respectively.

$\mathrm{He}$ is the author/co-author of over 160 technical papers, reports and 8 books, including 3 books are written in German and 1 book is written in English "Vector Control of Three-Phase AC Machines - System Development in the Practice" that is published by the Springer publisher in 2008 and reprinted for the first time in 6/2015.

His specific research interests are electrical drives and control, motion and robot control, space vector control for electrical machines, power electronics control, renewable energy control systems, digital control of electrical drives, modeling and simulation.

Int J Pow Elec \& Dri Syst, Vol. 10, No. 2, June 2019 : 720 - 730 